\section{Aumento intenso no uso do conector daí em Florianópolis: mudança por difusão?*}

Intense increase in the use of connector daí in Florianópolis: change trough diffusion?

Maria Alice TAVARES (UFRN) aliceflp@hotmail.com

Recebido em: 22 de abr. de 2019. Aceito em: 12 de jun. de 2019.

*Este trabalho está vinculado ao Projeto Mudança geracional versus difusão interdialetal: uma abordagem sociofuncionalista a conectores sequenciadores, que recebeu apoio do Conselho Nacional de Desenvolvimento Científico e Tecnológico/CNPq (processo $n^{\circ}$ 306684/2014-4).

\section{0}

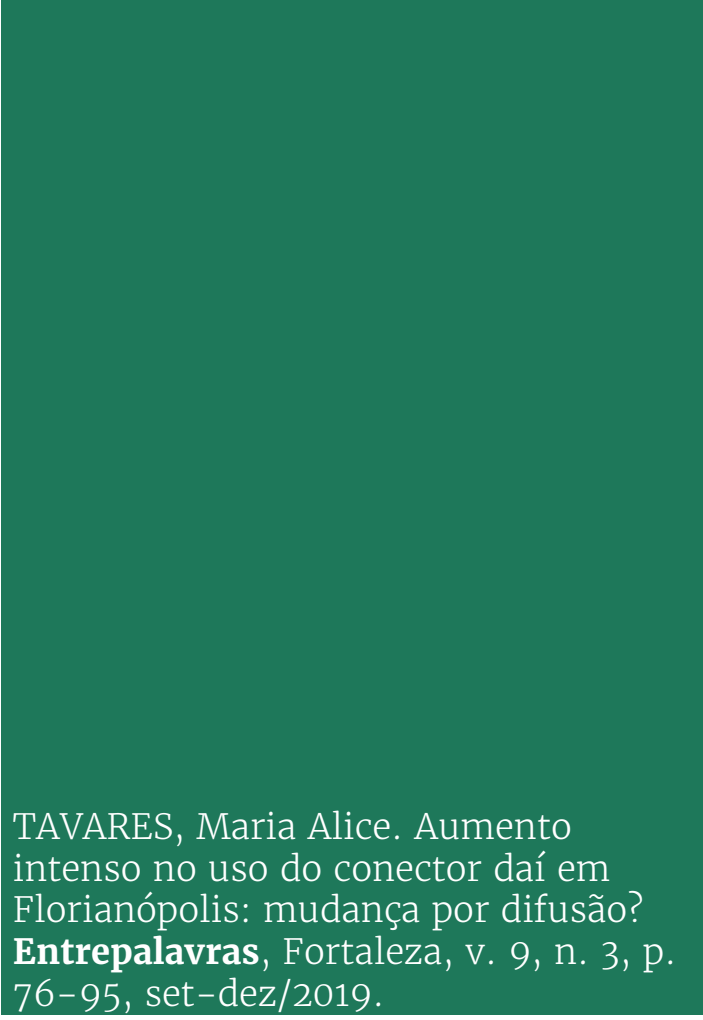

Resumo: À luz da sociolinguística variacionista, tomo os conectores e, aí, daí e então como variantes da função discursiva denominada "sequenciação retroativopropulsora de informações", responsável pelo estabelecimento de uma relação coesiva de continuidade e consonância entre enunciados. Tenho por objetivo reanalisar a distribuição do conector daí quanto ao sexo e à idade observada em Tavares (2003), correlacionando esses fatores embusca deuma explicação mais adequada para os padrões de distribuição obtidos. Os dados foram extraídos de 48 entrevistas sociolinguísticas do Banco de Dados VARSUL/Florianópolis (SC). Essas entrevistas foram feitas com informantes de ambos os sexos e de quatro grupos etários: 9 a 12 anos; 15 a 21 anos; 25 a 50 anos; mais de 50 anos. Os resultados revelam mudança intensa no sentido de o conector daí ser muito frequente entre pré-adolescentes de ambos os sexos e entre garotas adolescentes, mas ser de uso raro entre garotos adolescentes e entre mulheres e homens com mais de 25 anos. Esses padrões de distribuição sugerem mudança por difusão. Esse tipo de mudança ocorre quando falantes de diferentes línguas ou dialetos entram em contato. As garotas adolescentes foram o primeiro grupo a acelerar o uso do daí, portanto podem ser consideradas líderes do processo de difusão.

Palavras-chave: Difusão. Liderança feminina. Conectores sequenciadores. 
Abstract: Under the light of comparative variationist sociolinguistics, I take the connectors e, ai and então as variants of the discursive variable named "retroactivepropeller sequenciation of information", which is responsible for establishing a continuity and consonance cohesive link between utterances. I aim to reanalyze the distribution of connector daí regarding sex and age observed in Tavares (2003), correlating these factors in search for a more adequate explanation for the distribution patterns obtained. The data were draw from 48 sociolinguistic interviews from the VARSUL Data Base/Florianópolis (SC). These interviews were carried out with informants of both sexes and four age groups: 9 to 12 years old; 15 to 21 years old; 25 to 50 years old; more than 50 years old. The results show a vigorous shift in that the connector dai is frequent among preadolescents of both sexes and adolescent girls, but it is very rare among adolescent boys and among female and males over 25 years old. Such distributional patterns suggest change trough diffusion. This type of change occurs when speakers of different languages or dialects come in contact with each other. The adolescent girls were the first group to advance the usage of daí, so they can be considered leaders of the diffusion process.

Keywords: Diffusion. Female leadership. Sequence connectors.

\section{Introdução}

Neste texto, adotando como guia teórico-metodológico a sociolinguística variacionista, abordo uma função de natureza discursiva que se vincula ao plano da conexão textual. Essa função pode ser denominada "sequenciação retroativo-propulsora de informações" por envolver uma relação entre informações em que o enunciado subsequente representa a continuidade do discurso (propulsão) em consonância com o enunciado precedente (retroação).

Os conectores sequenciadores e, aí, daí e então são as formas mais recorrentes no papel de indicadores de sequenciação retroativopropulsora de informações no corpus que utilizo como fonte de dados. Trata-se de um corpus composto por 48 entrevistas sociolinguísticas pertencentes ao banco de dados Variação Linguística na Região Sul do Brasil (VARSUL), feitas ao longo da década de 1990 com informantes nativos do município de Florianópolis (SC). Esses informantes se distribuem homogeneamente em quatro faixas etárias: 9 a 12 anos; 15 a 21 anos; 25 a 50 anos; mais de 50 anos. ${ }^{1}$

Aos movimentos coesivos de propulsão e retroação discursiva característicos da sequenciação retroativo-propulsora de informações, somam-se três indicações semântico-pragmáticas: (i) sequenciação textual: ordenação sequencial das unidades discursivas sem que nuanças de significado mais específicas estejam salientes; (ii) sequenciação

\footnotetext{
${ }^{1}$ No Banco de Dados VARSUL, o corpus de Florianópolis da década de 1990 é o único que contém entrevistas feitas com informantes de 8 a 12 anos, grupo etário fundamental para o tipo de análise aqui proposto.
} 
v. 9 (3) 76-95 set-dez 2019

temporal: sinalização de sucessão temporal entre dois eventos, um referido na unidade discursiva anterior e outro na unidade discursiva posterior; (iii) consequência: introdução de informação que representa a consequência de uma causa mencionada previamente.

A seguir, (1) ilustra a sequenciação textual, (2) ilustra a sequenciação temporal e (3) ilustra a consequência:

(1) Só que tem que tomar cuidado por causa que ela é um gato de carne, né? daí quando vai pra rua os cachorros querem comer ela, né? daí a minha mãe tem cachorro, e ele avança nesse gato, nessa gata, quando o gato fica- vai pra casa os cachorros só ficam olhando, né? (FLPo8C) ${ }^{2}$

(2) Aí eu sei que a cabo de três dias, aí ele apareceu aqui, aí nós fomos lá no reitor, aí ele passou já o cheque, aí fui no banco, já recebi o dinheiro, já paguei pra ele e ficou tudo certo. (FLP05)

(3) E ela trabalha e estuda, então ela está sempre muito cansada, então sexta nem pensar, porque ela trabalha no sábado até às seis horas. E ela trabalha no sábado até as seis horas e está muito cansada, né? (FLP01J)

E, aí, daí e então tornaram-se conectores através de processos de gramaticalização ${ }^{3}$ que partiram de fontes adverbiais: (i) o e é proveniente do conector latino et, por sua vez oriundo do advérbio do latim arcaico et/ eti 'também' (COSERIU, 1977); (ii) o aí, o daí e o então derivam de fontes anafóricas espaciais e temporais latinas (SILVEIRA BUENO, 1965).

Embora o então fosse uma das formas codificadoras de sequenciação retroativo-propulsora de informações já nos séculos XIII e XIV, o aí e o daí passaram a atuar nessa função posteriormente e talvez apenas no português brasileiro, visto que, escrutinando quarenta textos escritos em português nos séculos XIII a XX, encontrei ocorrências desses conectores apenas em textos brasileiros do século XX - o aí a partir da

\footnotetext{
${ }^{2}$ No código (FLPO8C), tem-se FLP = informante natural de Florianópolis, 08 = número da entrevista. Nos casos em que há uma letra após o número da entrevista, pode haver $J$ = informante de 15 a 21 anos ou $C=$ informante de 9 a 12 anos.

3 Através da gramaticalização, um item lexical frequentemente utilizado em situações comunicativas particulares torna-se, no curso do tempo, um item gramatical, ou um item já gramatical adquire uma nova função gramatical (HOPPER; TRAUGOTT, 2003, p. 18). Com base em dados do latim e das várias fases da língua portuguesa, Tavares (2003) faz uma análise das etapas de gramaticalização de e, aí, daí e então como conectores.
} 
primeira metade e o daí a partir da segunda metade desse século; além disso, em amostras de fala do português europeu contemporâneo, não verifiquei a presença nem do aí, nem do daí (cf. TAVARES, 2003). O fato de que localizei o daí apenas na segunda metade do século XX pode ser um indício de que esse conector se desenvolveu mais tardiamente em relação ao aí, sendo, portanto, a forma mais recente na indicação de sequenciação retroativo-propulsora.

Apesar de desempenharem uma mesma função, os conectores e, aí, daí e então podem ser distinguidos no que se refere ao estilo das situações de interação em que eles aparecem com mais frequência. Como constatado através de questionários de avaliação estilística aplicados por Silva (2013) e Tavares (2003), os conectores mais novos aí e daí tendem a ser apontados como típicos de contextos de maior informalidade, ao passo que os conectores mais antigos $e$ e então são, em geral, considerados estilisticamente neutros quanto ao grau de formalidade da situação. ${ }^{5}$

Em pesquisa anterior (cf. TAVARES, 2003), obtive evidências de que estava em curso uma mudança na direção de um intenso aumento de uso do conector daí entre os pré-adolescentes (informantes de 9 a 12 anos) e adolescentes (informantes de 15 a 21 anos), em contraste com uma baixa utilização pelos indivíduos mais velhos. A distribuição do conector em apreço ao longo dos grupos etários foi a seguinte: (i) entre os pré-adolescentes, $60 \%$ de um total de 1146 dados; (ii) entre os adolescentes, $15 \%$ de um total de 1064 dados; (iii) entre os adultos de 25 a 50 anos, 3\% de um total de 1113 dados; (iv) entre os adultos com mais de 50 anos, $1 \%$ de um total de 977 dados.

Interpretei esses padrões de distribuição como indicando mudança por transmissão, porém atípica, uma vez que, nesse tipo de mudança, ocorre incremento gradual de uma forma a cada nova geração de falantes, o que não aconteceu com o daí. Diferentemente, neste estudo tenho por hipótese que a grande utilização do daí entre os grupos etários mais jovens em oposição à sua pouca recorrência entre os grupos etários mais velhos pode se enquadrar em outro tipo de mudança, a que se dá por difusão de uma forma advinda de uma comunidade externa.

\footnotetext{
${ }^{4}$ Além das formas aí e daí, também considerei, em minha busca em textos do século XIII ao XX: (i) as variações formais hy, y e ahi para aí; (ii) dhi, $d y$, di e dj para daí; (iii) entõ, enton e entonce para então. (cf. TAVARES, 2003).

5 Cumpre ressalvar que, para alguns informantes florianopolitanos, o então é uma forma prestigiada, propícia para situações de interação de maior grau de formalidade (cf. TAVARES, 2003).
} 
v. 9 (3) 76-95 set-dez 2019

Labov (2001) afirma que o sexo tem papel significativo nos processos de mudança linguística. Tanto nos casos de transmissão quanto nos de difusão, as mulheres desempenham papel central como líderes do avanço da mudança. Segundo postula Labov (2007), os padrões de distribuição de formas variantes entre mulheres de faixas etárias variadas podem trazer subsídios para a definição do tipo de mudança, se disseminação ou difusão.

Considerando que as mulheres geralmente são as líderes de seu grupo etário na vanguarda da mudança, tenho por objetivo reanalisar os padrões de distribuição do conector daí observados em Tavares (2003) quanto ao sexo e à idade. A expectativa é a de que correlacionar esses dois fatores sociais permite delimitar com mais precisão o tipo de mudança pela qual passava o conector em foco na Florianópolis de 1990.

Uma vez que meu objetivo é reanalisar os resultados de Tavares (2003) em busca de uma explicação mais adequada para o uso intenso do conector daí pelos pré-adolescentes e adolescentes florianopolitanos, o corpus utilizado é o mesmo, embora os dados tenham passado por revisão para o estudo que ora se reporta, como pode ser conferido na seção referente à análise dos resultados.

O texto está organizado do seguinte modo: inicialmente, trato da questão da liderança feminina em processos de mudança linguística; a seguir, procedo à análise dos resultados quantitativos; na sequência, discuto esses resultados. Por fim, apresento as considerações finais e as referências.

\section{Mudança por transmissão e mudança por difusão: o papel das mulheres}

Inúmeras pesquisas feitas sob a égide da sociolinguística variacionista têm mostrado que as escolhas linguísticas de mulheres e homens podem ser ótimos indícios de mudança em andamento. $\mathrm{Na}$ maioria das mudanças linguísticas já analisadas, são as mulheres que ocupam o posto de liderança. Os homens, embora também participem da implementação das mudanças, podem estar até uma geração inteira atrás das mulheres. Apenas quando os processos de mudança se aproximam da finalização, acontece a redução gradual da diferença entre homens e mulheres (LABOV, 1990, 2001). Naturalmente, distinções quanto ao sexo devem ser avaliadas a cada caso, lançando-se um olhar atento "às estruturas sociais, aos contextos externos, à natureza da mudança e a quem as conduz adiante" (TAGLIAMONTE; D'ARCY, 2009, p. 100). ${ }^{6}$

6"to social structures, external contexts, the nature of change, and who carries them forward" (TAGLIAMONTE; DARCY, 2009, p. 100). 
Levando em conta esses elementos, Labov (2001) propõe quatro princípios que envolvem o papel do sexo na variação linguística:

Princípio 1: as mudanças linguísticas que ocorrem abaixo do nível de percepção consciente (change from below) geralmente se originam em um grupo socioeconômico intermediário no interior da própria comunidade de fala, como a classe média baixa, que apresenta as frequências mais altas da forma inovadora;

Princípio 2: em situações de variação estável, as mulheres, em média, manifestam um menor desvio em relação à norma de prestígio de sua comunidade de fala em contraste com os homens;

Princípio 3: nas mudanças linguísticas que ocorrem acima do nível de percepção consciente (change from above), as mulheres tendem a adotar variantes inovadoras (geralmente prestigiadas) que estão em processo de difusão, vindas de outras comunidades de fala (com acomodação a um padrão externo, portanto), ao passo que os homens tendem a dar preferência a variantes locais;

Princípio 4: nas mudanças linguísticas que ocorrem abaixo do nível de percepção consciente (change from below), as mulheres fazem maior uso das variantes inovadoras.

Labov (2007, p. 346) assim distingue esses dois tipos de mudança: change from above é "a importação de elementos de outros sistemas" e change from below é "o tipo normal de mudança linguística interna",7 cuja origem está no sistema da própria comunidade de fala. Nesse caso, ocorre a transmissão dos traços linguísticos das gerações mais velhas para as gerações mais jovens, e a mudança evolui gradualmente por incrementação da frequência de uso da forma inovadora a cada nova geração. Assim, a distribuição dessa forma em grupos etários distintos revelará um padrão de mudança que progride no formato de um declive monotônico: há um avanço regular da mudança, com elevação paulatina da taxa de uso da forma inovadora à medida que diminui a idade dos indivíduos (cf. LABOV, 2001).

7 "the importation of elements from other systems"; "normal type of internal language change" (LABOV, 2007, p. 346). 
v. 9 (3) 76-95 set-dez 2019

Em contraste, quando a mudança envolve a difusão de uma forma proveniente de outra comunidade de fala, a alteração na frequência de emprego da forma inovadora pode ser abrupta, ocasionando uma divisão dramática entre grupos particulares da comunidade de fala, incluindo os distintos grupos etários (BUCHSTALLER, 2006; TAGLIAMONTE, 2012). Kerswill et al. (2013) esclarecem que, quando um traço linguístico é majoritariamente utilizado pelos jovens, sua adoção não se realizou por transmissão direta dos pais, e sim por difusão via contato com falantes de comunidades externas. Segundo os autores, "o que caracteriza os cenários de contato é que há uma descontinuidade linguística entre gerações" (KERSWILL et al., 2013, p. 266). ${ }^{8}$

Labov (2001) assevera que, quando a mudança se dá por difusão interdialetal ou interlinguística, os falantes tendem a perceber que há uma mudança em andamento, e a variante inovadora, avaliada positivamente pela comunidade, tem seu aumento de uso capitaneado pelas mulheres. Em oposição, quando a mudança se desenvolve abaixo do nível de consciência (por transmissão geracional), os falantes costumam não perceber que há uma mudança em andamento, e as mulheres tomam a liderança no emprego da variante inovadora, seja ela prestigiada ou não (LABOV, 2001; MEYERHOFF, 2006). ${ }^{9}$ De qualquer modo, seja nos casos de transmissão, seja nos casos de difusão, as mulheres são, em geral, as condutoras do processo de mudança: elas "lideram 90\% das inovações da língua onde quer que elas tenham origem" (TAGLIAMONTE, 2012, p. 63, tradução nossa). ${ }^{10}$

Cabe um alerta no que toca à questão do nível de percepção dos falantes. Guy (2011) pondera que as pesquisas feitas no âmbito da sociolinguística variacionista:

confirmam a necessidade de reconhecimento de tipos distintos de mudança, baseados em diferentes mecanismos, mas o critério específico de consciência é de utilidade duvidosa para essa distinção, uma vez que há mudanças envolvendo inovações espontâneas das quais há considerável percepção consciente [...], e mudanças envolvendo acomodações a modelos externos em que os falantes mostram pouca percepção a respeito (GUY, 2011, p. 180, tradução nossa). ${ }^{11}$

\footnotetext{
8 "what characterizes contact scenarios is that there is a linguistic discontinuity between generations" (KERSWILL et al, 2013, p. 266).

9 Explicações de diferentes naturezas têm sido propostas para o comportamento feminino no que diz respeito à utilização de formas prestigiadas e não prestigiadas, como pode ser conferido em Cheshire (2003), Labov (1990, 2001, 2010), Meyerhoff (2006), entre outros.

10 "women lead in $90 \%$ of the innovations of language wherever they originate" (TAGLIAMONTE, 2012, p. 63).

11 "confirms the need to recognise distinct types of change, based on different social
} 
O grau de prestígio da forma inovadora também não pode ser tomado como uma característica delimitadora das mudanças por transmissão e por difusão, posto que nem sempre uma forma vinda de uma fonte externa à comunidade é prestigiada. Esse é o caso do daí, que, assim como o aí, tende a ter seu emprego diminuído ou mesmo evitado em contextos de maior formalidade, seja na fala ou na escrita, o que não acontece com o e e o então, estilisticamente marcados como neutros (SILVA, 2013; TAVARES, 2003). De acordo com Guy (2011), os casos de difusão em que a forma inovadora não é prestigiada podem ser, em geral, explicados pela dinâmica social da comunidade receptora, incluindo questões de construção identitária e tipos variados de afiliações a redes sociais.

Não raro, a distinção entre mulheres e homens quanto à distribuição das formas variantes manifesta interação com outros tipos de distinções sociais relevantes para a comunidade. Por isso, ao se tomar apenas a fala de mulheres e de homens em geral, perde-se a oportunidade de se observar com minúcia as etapas de desenvolvimento de uma mudança linguística em progresso. Já a combinação do sexo com outros fatores de natureza social, como faixa etária, grau de escolarização, classe social, etnia etc., permite notar diferenças passíveis de existir entre conjuntos mais específicos de mulheres e homens.

Na sequência, apresento a análise dos resultados obtidos através da combinação do sexo com a faixa etária, o que permitiu examinar de maneira mais detalhada o fenômeno de mudança envolvendo o conector daí na fala de Florianópolis.

\section{Análise dos resultados: uso do daí na fala jovem em Florianópolis}

Em Tavares (2003), foram analisados um total de 4.300 dados, englobando e, aí, daí e então. Para o estudo aqui apresentado, 267 dados foram excluídos, resultando num total de 4.033.12 Foram controlados como condicionadores da seleção entre e, aí, daí e então para a indicação

mechanisms, but the specific criterion of consciousness is of doubtful utility in making the distinction, since there are changes involving spontaneous innovations of which there is considerable conscious awareness [...], and changes involving accommodations to external models that speakers show little awareness of" (GUY, 2011, p. 180).

${ }^{12}$ Os dados excluídos foram, em sua maioria, casos do e em contextos de sequenciação textual no nível oracional, em que a substituição desse conector pelos demais era possível, mas poderia dar a impressão de certa diminuição no grau de conexão existente entre as orações. A exclusão não resultou em diferenças no padrão de distribuição dos conectores pelos grupos de fatores controlados, e pouco alterou os pesos relativos. 
v. 9 (3) 76-95 set-dez 2019

de sequenciação retroativo-propulsora de informações os mesmos grupos de fatores do estudo anterior: sexo, idade, nível de escolaridade, indicação semântico-pragmática, nível de articulação, grau de conexão e sequência textual. ${ }^{13}$

Submeti os dados a tratamento estatístico através do programa GOLDVARB X (SANKOFF; TAGLIAMONTE; SMITH, 2005), para cálculo de frequências, percentuais e pesos relativos, e para identificação da ordem de significância dos fatores considerados.

O peso relativo é uma medida multivariada frequentemente utilizada na pesquisa variacionista. Essa medida resulta do controle simultâneo de elementos contextuais (no formato de múltiplas variáveis independentes/grupos de fatores) que podem influenciar o fenômeno variável. Em uma análise multivariada, "(...) cada efeito de um fator na análise é calculado enquanto são controlados, até o máximo possível, os outros fatores" (GUY; ZILLES, 2007, p. 100). Os pesos relativos variam de o a 1. Quanto mais próximo de 0 , menos influente é o fator que o recebeu; quanto mais próximo de 1, maior é a influência. Um peso de 0.50 tende a ser indiferente, mas,

embora isso geralmente seja verdadeiro, não é o modo mais preciso de se conceber os pesos dos fatores. [...] a posição relativa dos pesos em relação uns aos outros é que é o critério relevante para a interpretação dos resultados (TAGLIAMONTE, 2006, p. 145, tradução nossa). ${ }^{14}$

Os resultados provêm de três rodadas binárias do programa, considerando, a cada rodada, uma das variantes versus as demais (isto é, e versus aí, daí e então; aí versus e, daí e então; daí versus e, aí e então; e então versus e, aí e daí). Esse procedimento é necessário porque o GOLDVARB X não realiza rodadas multinomiais (TAGLIAMONTE, 2006). ${ }^{15}$ Neste texto, detenho-me nos fatores sexo e idade.

\footnotetext{
${ }_{13}$ Para informações detalhadas a respeito da caracterização dos grupos de fatores linguísticos e discursivos, confira-se Tavares (2018). Desses grupos, foram apontados pelo GOLDVARB X como significativos para a escolha entre $e$, aí, daí e então a indicação semântico-pragmática, o nível de articulação e a sequência textual. Entre os grupos sociais, além da idade, foi considerado significativo o nível de escolaridade (cf. TAVARES, 2018).

${ }_{14}$ "while this is generally true, it is not the most accurate way to conceive of factor weights. Instead, it is the relative position of factors weights, vis-à-vis each other, that is the relevant criterion for interpreting the results" (TAGLIAMONTE, 2006, p. 145).

15 Tagliamonte (2006) informa que nunca foi implementada a opção de rodada multinominal, embora ela exista no menu "CELLS" do Goldvarb X. A autora informa também que poucos estudos variacionistas se valeram de análises multinominais.
} 
A tabela 1 traz os resultados referentes ao sexo, extraídos de uma rodada estatística que incluiu todos os fatores supracitados. Nessa rodada, o sexo não foi selecionado, pelo GOLDVARB X, como significativo para nenhum dos conectores.

A tabela 2, por sua vez, traz os resultados referentes ao cruzamento entre sexo e idade extraído de rodadas em que esse cruzamento foi incluído como um oitavo fator. ${ }^{16} \mathrm{O}$ sexo controlado isoladamente continuou não sendo selecionado, mas o cruzamento entre sexo e idade teve grande significância: foi selecionado em primeiro lugar para o aí, o daí e o então, e em terceiro lugar para o $e$.

Tabela 1 - Distribuição de e, aí, daí e então quanto ao sexo

\begin{tabular}{c|c|c|c|c|c|c|c|c|c|c|c|c}
\cline { 2 - 13 } & \multicolumn{4}{|c|}{$E$} & \multicolumn{4}{c|}{ AÍ } & \multicolumn{3}{c|}{ DAÍ } & \multicolumn{3}{c}{ ENTÃO } \\
\hline Sexo & Ap./Tot. & $\%$ & PR & Ap./Tot. & $\%$ & PR & Ap./Tot. & $\%$ & PR & Ap./Tot. & $\%$ & PR \\
\hline Feminino & $879 / 2.083$ & 42 & 0.52 & $465 / 2.083$ & 22 & 0.50 & $411 / 2.083$ & 20 & 0.47 & $328 / 2.083$ & 16 & 0.47 \\
\hline Masculino & $706 / 1.950$ & 36 & 0.47 & $433 / 1.950$ & 22 & 0.49 & $450 / 1.950$ & 23 & 0.52 & $361 / 1.950$ & 19 & 0.52 \\
\hline TOTAL & $1.585 / 4.033$ & 40 & & $898 / 4.033$ & 22 & & $861 / 4.033$ & 21 & & $689 / 4.033$ & 17 & \\
\hline
\end{tabular}

Fonte: elaborada pelo autor.

As pequenas variações entre os percentuais e entre os pesos relativos, todos situados nas proximidades do ponto neutro de 0.50 , mostram que o sexo é de pouca relevância: as escolhas dos florianopolitanos e das florianopolitanas, no que concerne aos conectores sequenciadores, é muito semelhante, ao se levar em conta apenas os dois sexos num plano isolado e global.

Tabela 2 - Cruzamento entre sexo e idade

\begin{tabular}{c|c|c|c|c|c|c|c|c|c|c|c|c}
\hline \multirow{2}{*}{$\begin{array}{c}\text { Idade/ } \\
\text { Sexo }\end{array}$} & \multicolumn{4}{|c|}{$E$} & \multicolumn{4}{|c|}{ AI } & \multicolumn{3}{c|}{ DAÍ } & \multicolumn{3}{c}{ ENTÃO } \\
\cline { 2 - 13 } & Ap./Tot. & $\%$ & PR & Ap./Tot. & $\%$ & PR & Ap./Tot. & $\%$ & PR & Ap./Tot. & $\%$ & PR \\
\hline 9 a 12 F & $173 / 490$ & 35 & 0.49 & $94 / 490$ & 19 & 0.40 & $211 / 490$ & 43 & 0.85 & $12 / 490$ & 03 & 0.20 \\
\hline 9 a 12 M & $127 / 598$ & 21 & 0.39 & $48 / 598$ & 08 & 0.31 & $420 / 598$ & 70 & 0.95 & $03 / 598$ & 01 & 0.05 \\
\hline 15 a 21 F & $220 / 515$ & 43 & 0.49 & $62 / 515$ & 12 & 0.32 & $171 / 515$ & 33 & 0.86 & $62 / 515$ & 12 & 0.50 \\
\hline 15 a 21 M & $221 / 512$ & 43 & 0.52 & $223 / 512$ & 44 & 0.69 & $18 / 512$ & 03 & 0.24 & $50 / 512$ & 10 & 0.49 \\
\hline 25 a 50 F & $267 / 646$ & 42 & 0.52 & $228 / 646$ & 35 & 0.61 & $21 / 646$ & 03 & 0.20 & $130 / 646$ & 20 & 0.57 \\
\hline 25 a 50 M & $156 / 398$ & 39 & 0.48 & $62 / 398$ & 16 & 0.42 & $6 / 398$ & 01 & 0.14 & $174 / 398$ & 44 & 0.80 \\
\hline + de 50 F & $219 / 432$ & 50 & 0.58 & $81 / 432$ & 19 & 0.48 & $8 / 432$ & 02 & 0.18 & $124 / 432$ & 29 & 0.75 \\
\hline + de 50 M & $202 / 442$ & 46 & 0.58 & $100 / 442$ & 23 & 0.52 & $6 / 442$ & 01 & 0.12 & $134 / 442$ & 30 & 0.76 \\
\hline TOTAL & $1.585 / 4.033$ & 40 & & $898 / 4.033$ & 22 & & $861 / 4.033$ & 21 & & $689 / 4.033$ & 17 & \\
\hline
\end{tabular}

Fonte: elaborada pelo autor.

${ }_{16}$ Em um cruzamento, dois fatores são cruzados, isto é, combinados de todos os modos possíveis. No caso do sexo e da idade, temos, neste estudo, feminino e 9 a 12 anos, feminino e 15 a 21 anos etc. A cada combinação é atribuído um peso relativo. 
v. 9 (3) 76-95 set-dez 2019

Delimitei as quatro faixas etárias de acordo com as fases da vida cujas características foram descritas por Chambers (1995): de 9 a 12 anos (crianças ou pré-adolescentes, em pleno processo de alinhamento a um grupo de amigos); de 15 a 21 anos (envolvimento em grupos adolescentes, início e finalização da escolarização secundária e orientação ao grupo de trabalho mais amplo e/ou universidade); de 25 a 45 anos (emprego regular e/ou responsabilidades familiares); acima de 50 anos (diminuição da força de trabalho e aposentadoria).

Mulheres e homens com mais de 50 anos de idade se comportam de modo similar ao favorecer o aparecimento do $e$ em sua fala (com frequências de $51 \%$ e $45 \%$, respectivamente, e peso relativo de 0.58). Garotos de 9 a 12 anos (pré-adolescentes) representam o grupo que menos se vale do conector em apreço (com frequência de $21 \%$ e peso relativo de 0.39), ao passo que os demais grupos se mostram relativamente indiferentes no que tange a esse conector.

$\mathrm{O}$ aí tem seu emprego positivamente condicionado na fala de mulheres da faixa etária de 25 a 50 anos (com frequência de 35\% e peso relativo de 0.61) e, um pouco mais, por garotos da faixa etária de 15 a 21 anos (adolescentes) (com frequência de $44 \%$ e peso relativo de 0.69). O uso desse conector é restringido entre homens de 25 a 50 anos (com frequência de $16 \%$ e peso relativo de 0.42 ), assim como entre as garotas adolescentes (com frequência de $12 \%$ e peso relativo de 0.32 ) e entre os pré-adolescentes de ambos os sexos (com frequência de $19 \%$ e peso relativo de 0.40 para as garotas, e com frequência de $8 \%$ e peso relativo de 0.31 para os garotos). Mulheres e homens com mais de 50 anos de idade representam grupos neutros no que diz respeito à preferência pelo aí (com frequências de $19 \%$ e $23 \%$ e pesos relativos de 0.48 e 0.52 , respectivamente).

O daí é fortemente desfavorecido na fala dos quatro grupos etários mais velhos, contando, nesses grupos, com frequências de apenas $1 \%$ a $3 \%$ e pesos relativos de 0.12 a 0.20 . Entre os garotos adolescentes, o daí também é largamente desfavorecido, com frequência e peso relativo similares aos dos indivíduos mais velhos: $3 \%$ de frequência e peso relativo de 0.24 . Em contraste, esse conector é largamente favorecido na fala dos demais grupos: (i) as garotas adolescentes (com frequência de $33 \%$ e peso relativo de 0.86); (ii) as garotas pré-adolescentes (com frequência de $43 \%$ e peso relativo de 0.85); e (iii) os garotos pré-adolescentes (com frequência de 70\% e peso relativo de 0.95). 
É premente destacar que o único grupo etário em que houve divergência no padrão de distribuição do daí entre mulheres e homens foi o dos adolescentes, com as garotas servindo-se desse conector de forma intensa e os garotos seguindo o padrão de pouco uso dos informantes com mais de 25 anos de ambos os sexos.

Três dos grupos etários mais velhos manifestam uma forte inclinação à utilização do então: mulheres e homens com mais de 50 anos e homens de 25 a 50 anos. Esses grupos apresentam frequências entre $29 \%$ a $44 \%$ e pesos relativos entre 0.75 a 0.80 . Mulheres de 25 a 50 anos também se valem do conector em enfoque, mas com menor intensidade (com frequência de $20 \%$ e peso relativo de 0.57). Os adolescentes de ambos os sexos revelam indiferença quanto ao então, diagnosticada através de pesos relativos em torno do ponto neutro. Por fim, entre garotas e garotos pré-adolescentes, o então é altamente desfavorecido (com frequências de $1 \%$ e $3 \%$ e pesos relativos de 0.05 e 0.20 , respectivamente).

Em síntese, o conector mais recente, daí, tem uso significativo na amostra de dados considerada, apenas na fala de três grupos de indivíduos jovens, as garotas adolescentes e os pré-adolescentes de ambos os sexos. Nos demais grupos, o emprego desse conector é extremamente baixo. O segundo conector mais recente, aí, recebe destaque na fala de dois grupos etários: mulheres de 25 a 50 anos e homens de 15 a 25 anos. O e e o então, conectores mais antigos, sobressaem-se na fala dos dois grupos etários mais maduros, mulheres e homens com mais de 50 anos, e o então também se destaca na fala de mulheres e homens de 25 a 50 anos.

Na próxima seção, os resultados obtidos são avaliados quanto à possibilidade de uma mudança por difusão estar envolvida no avanço de uso do conector daí na comunidade de fala de Florianópolis.

\section{Discussão dos resultados}

Como esperado, a distribuição do conector daí na fala de mulheres e homens dos quatro grupos etários aqui levados em conta não se enquadra no padrão de incrementação gradual intergeracional típico da mudança por transmissão, em que ocorre aumento de uso da forma inovadora a cada nova geração mais jovem.

Houve emprego intenso do daí por garotas adolescentes e por pré-adolescentes de ambos os sexos, em contraste com sua pouca 
v. 9 (3) 76-95 set-dez 2019

ocorrência entre os demais grupos controlados. Esse resultado confirma a hipótese inicial de que haveria um alto uso do daí entre os dois grupos etários mais jovens em contraste a um baixo uso entre os dois grupos etários mais velhos. Tal padrão de distinção entre jovens e adultos é característico da mudança por difusão.

Como já mencionado, a mudança por difusão acontece em comunidades em que falantes de diferentes línguas ou dialetos entram em contato e pode envolver uma notável diferença na distribuição de formas inovadoras entre grupos distintos de membros da comunidade. Por exemplo, se o grupo introdutor da mudança for o dos adolescentes, eles utilizarão a forma inovadora com frequência, ao passo que os indivíduos mais velhos não a utilizarão ou, dependendo do seu grau de contato com os adolescentes, empregá-la-ão em pequena quantidade (BUCHSTALLER, 2006; CUKOR-ÁVILA, 2012; TAGLIAMONTE, 2005).

Esse parece ser o caso da sequenciação retroativo-propulsora em Florianópolis: há uma mudança abrupta nos padrões de distribuição do conector daí entre as faixas etárias de 15 a 21 anos e as faixas etárias mais velhas. Esse conector tem poucas ocorrências entre os informantes com mais de 25 anos de ambos os sexos (com frequências de 1\% a 3\%), mas é bastante recorrente entre os informantes de 15 a 21 anos (com 18\% dos 1027 dados desse grupo etário, somando-se mulheres e homens), tendo sua frequência aumentada ainda mais entre os informantes de 8 a 12 anos (com 58\% dos 1088 dados desse grupo etário, somando-se meninos e meninas).

No caso dos informantes adolescentes de 15 a 21 anos, a liderança do processo de mudança é claramente feminina: elas foram responsáveis por 171 (90\%) dos 189 dados do daí produzidos pelo grupo adolescente, ao passo que eles foram responsáveis por 18 (10\%). Já a distribuição entre os pré-adolescentes revela um maior uso do daí entre os garotos, que contaram com 420 entre os 631 dados (67\%) referentes a esse grupo etário, em contraste com as garotas, com 211 dados (33\%).

Tais resultados podem ser tomados como indícios de que, no caso do conector daí em Florianópolis, não houve uma transmissão regular de geração para geração com um incremento gradual, a cada nova geração, desse conector. Ao invés, os resultados apontam para uma mudança do tipo "dramática", mais comum em casos de difusão interdialetal. 
O contato das adolescentes florianopolitanas com indivíduos utentes de dialetos caracterizados por emprego significativo do daí17 (possivelmente indivíduos da mesma faixa etária vindos de fora) pode ter sido o que levou à difusão dessa forma na comunidade de fala de Florianópolis.

Um exemplo de adolescente do sexo feminino que tem contato com jovens de fora é S., uma das maiores usuárias do daí. Vejamos alguns trechos de sua entrevista que comprovam esse contato: ${ }^{18}$

(4) E: E essas amigas que moram fora? Como é que tu te correspondes com elas? Por cartas?

I: Com cartas, ela vem aqui, porque essa de Curitiba eu conheci porque a minha mãe é muito amiga da mãe dela, a gente se conheceu pequena, e ela- ou ela vem aqui, ou eu vou pra lá. E a de Joinville, ela morava aqui, estudava comigo na quinta série, e eu reencontrei ela esse ano, na Refinaria quando a gente saiu, daí eu falei com ela, daí ano que vem ela vai $\mathrm{m}$ - morar aqui e vai estudar comigo também. ${ }^{19}$

Outro estudo variacionista, frente a resultados similares no que se refere à distribuição social das formas, também propôs a difusão interdialetal como propulsora da mudança. Com base em dados extraídos de entrevistas sociolinguísticas do Banco de Dados VARSUL referentes ao município de Florianópolis, Pagotto (2004) analisou a variação na realização das oclusivas alveolares e concluiu que um processo de contato linguístico estava subjacente a esse fenômeno variável. Segundo o autor, uma das variantes, a africada palatal,

é fortemente identificada com a fala dos migrantes de classe média, enquanto a forma não africada pode ser colocada como a forma conservadora, apontada pela dialetologia local como a forma característica da cidade (PAGOTTO, 2004, p. 35).

\footnotetext{
${ }_{17}$ Por hipótese, tais dialetos são de comunidades de fala mais próximas de Florianópolis, dos estados do Rio Grande do Sul e do Paraná, e do interior do estado de Santa Catarina. Um estudo futuro pode ser mais esclarecedor a esse respeito.

${ }_{18}$ Mais informantes com contatos externos à comunidade podem ser identificados em estudo futuro, através das entrevistas sociolinguísticas já prontas, mas também através de questionamentos feitos diretamente aos informantes, em que deve ser indagada a origem desses contatos.
}

${ }^{19}$ O código E se refere ao entrevistador; e o código I, ao informante. 
v. 9 (3) 76-95 set-dez 2019

Pagotto (2004) defende que Florianópolis se tornou palco de contato linguístico devido à migração de habitantes de estados como Rio Grande do Sul, Paraná, Rio de Janeiro e São Paulo, bem como de habitantes de outras regiões do estado de Santa Catarina. O autor informa que a "migração de tais regiões tem sido apontada em diversos trabalhos (cf. FANTIN, 2000, dentre outros) como de pessoas de classe média atraídas pelos índices de qualidade de vida que a cidade tem registrado" (PAGOTTO, 2004, 190).

Devido a essa intensa migração, os estudos de variação que se voltam para dados de fala da capital catarinense - caso desta pesquisa - precisam levar em consideração a possibilidade de que o contato linguístico possa estar subjacente ao fenômeno variável investigado, com a difusão interdialetal de formas trazidas por migrantes de outros estados e mesmo de outras regiões de Santa Catarina.

Embora Pagotto (2004) aborde uma variável de nível fonológico, os resultados obtidos por ele são comparáveis aos obtidos neste estudo. Os princípios de mudança propostos por Labov (2001) são gerais, válidos para qualquer fenômeno variável, inclusive os de nível discursivo (cf. TAGLIAMONTE, 2012), caso dos conectores sequenciadores. ${ }^{20}$

O princípio que se aplica aos resultados obtidos por ambos os estudos é o de número 3, que prevê que, nas mudanças por difusão (change from above), são as mulheres que costumam adotar as formas inovadoras provindas de comunidades de fala externas. Os homens, por sua vez, empregam mais as variantes típicas de sua comunidade de fala.

No entanto, há uma diferença quanto à natureza da variante inovadora. Em Pagotto (2004), como previsto pelo princípio de número 3, a variante externa à comunidade, a africada palatal, é uma forma prestigiada por aqueles que a utilizam recorrentemente. No caso dos conectores sequenciadores, a variante externa à comunidade, o daí, é avaliada como informal, isto é, de menor prestígio (cf. TAVARES, 2003). Contudo, isso não é empecilho para a interpretação dos resultados referentes aos conectores sequenciadores como apontando para uma mudança por difusão, visto que, como pontua Guy (2011), existem situações de difusão em que a forma inovadora não é prestigiada.

Como o conector daí teria sido difundido para Florianópolis? Possivelmente via migrantes de regiões do Paraná e do Rio Grande do

${ }^{20}$ A generalidade dos princípios de mudança permite que se chegue a uma descrição holística de padrões de variação e mudança que abranja todos os componentes da gramática. 
Sul e de regiões do interior de Santa Catarina, em que seu uso é de grande recorrência (cf. TAVARES, 2018). Uma investigação preliminar em entrevistas do Banco de Dados VARSUL gravadas na década de 1990 em diferentes comunidades de fala dos referidos estados revela haver utilização, muitas vezes intensa, do conector daí na fala de informantes das faixas etárias de 25 a 50 anos e de mais de 50 anos em algumas dessas comunidades (cf. TAVARES, 2018). ${ }^{21}$

Ou seja, em tais comunidades, a mudança parece ter se dado bem antes do que em Florianópolis, já estando esse conector presente, com grande frequência, no sistema linguístico de indivíduos de todas as idades. Uma dessas comunidades é a de Lages (SC). Uma das informantes lageanas da faixa etária de 25 a 50 anos utiliza o daí como conector mais de 150 vezes em uma entrevista de cerca de 60 minutos de duração. Há outras entrevistas na mesma comunidade de fala, inclusive com pessoas da faixa etária acima de 50 anos, que contam com mais de 100 ocorrências do daí em suas entrevistas. Não houve registro de um uso tão frequente do daí em uma única entrevista na amostra de Florianópolis, mesmo entre seus maiores usuários, os meninos de 9 a 12 anos (cf. TAVARES, 2018).

Ao migrarem para Florianópolis, falantes de comunidades em que o daí já era bastante utilizado podem ter se tornado a fonte da difusão desse conector. Como observado neste estudo, garotas de 15 a 21 anos eram, na década de 1990, as líderes locais do processo de mudança sob enfoque. Portanto, é possível que a difusão tenha sido iniciada através do contato dessas garotas com pessoas de fora da comunidade, em ambientes como escola, universidade e trabalho, por exemplo.

Os adolescentes - e, especialmente, as adolescentes, pois a maioria das mudanças linguísticas têm liderança feminina - são excelentes candidatos a introdutores de mudança linguística em um processo de difusão interdialetal por estarem em um período da vida sujeito à grande influência do grupo de pares, que pode contar com membros externos à comunidade: as redes sociais ${ }^{22}$ adolescentes costumam ser mais amplas e, em decorrência, mais abertas a

21 Não há grupos de informantes com menos de vinte e cinco anos disponíveis para a maioria das comunidades de fala em que foram gravadas entrevistas sociolinguísticas para a constituição do Banco de Dados VARSUL na década de 1990. O corpus de Lages, por exemplo, não tem informantes dessa faixa etária.

${ }^{22}$ No âmbito da sociolinguística, estudos voltados a redes sociais analisam o conjunto de relações que um indivíduo mantém com outros indivíduos em diferentes contextos (família, escola, trabalho etc.) (cf. MILROY, 2003). 
v. 9 (3) 76-95 set-dez 2019

influências externas (ANDROUTSOPOULOS, 2005). Daí pode advir uma "diferenciação linguística dramática" (TAGLIAMONTE, 2005, 1896)²3 em relação aos membros mais velhos da comunidade de fala, como se deu com o daí em Florianópolis. Contudo, o corpus utilizado nesta pesquisa não controla as redes sociais dos informantes. Assim, o papel das redes no processo de difusão do daí merece estudo posterior, com o mapeamento de contato com membros externos à comunidade, o que, por hipótese, seria mais frequente nas redes das mulheres adolescentes que fizeram uso intenso do daí.

Os resultados obtidos apontam para uma rápida adoção do daí pelos pré-adolescentes depois de sua introdução pelas garotas adolescentes via contato dialetal. É possível que essa adoção tenha sido resultado não mais de mudança por difusão, e sim de mudança por transmissão. Cukor-Avila e Bailey (2011) informam que "a difusão é um evento único. Ou seja, uma forma se difunde em uma geração e, se ela aparece na próxima, isso ocorre através da transmissão" (CUKORAVILA; BAILEY, 2011, p. 41, tradução nossa). ${ }^{24}$

É importante notar que, no processo de adoção do daí pelos pré-adolescentes, não há, ao contrário do que se verifica com os adolescentes, divergência no padrão de distribuição entre os sexos. $\mathrm{O}$ daí teve alta incidência tanto entre as garotas quanto entre os garotos (com frequências de $43 \%$ e $70 \%$ e pesos relativos de 0.85 e 0.95 , respectivamente), passando a ser mais frequente entre os garotos.

Esse uso intenso do daí será mantido pelas próximas gerações de florianopolitanos? Embora apenas pesquisas futuras feitas com base em dados de gerações mais recentes possam trazer evidências a esse respeito, acredito que essa manutenção vá acontecer, uma vez que, como já dito, em Lages, no mesmo estado, há falantes das faixas etárias mais velhas, 25 a 50 anos e mais de 50 anos, que recorrem amplamente ao daí.

\section{Considerações finais}

Neste texto, analisei os padrões de distribuição do conector daí na fala de oito conjuntos de florianopolitanos: (i) entre os préadolescentes, as garotas de 9 a 12 anos e os garotos de 9 a 12 anos; (ii)

\footnotetext{
23 "dramatic linguistic differentiation" (TAGLIAMONTE, 2005, 1896).

24 "diffusion is a "one-time" event. That is, a form diffuses in one generation and if it appears in the next it does so through transmission" (CUKOR-AVILA; BAILEY, 2011, p. 41).
} 
entre os adolescentes, as garotas de 15 a 21 anos e os garotos de 15 a 21 anos; (iii) entre os adultos, as mulheres de 25 a 50 anos, os homens de 25 a 50 anos, as mulheres de mais de 50 anos e os homens de mais de 50 anos.

Os resultados trouxeram indícios de um processo de mudança em que três dos grupos mais jovens passaram a fazer grande uso do daí: pré-adolescentes de ambos os sexos e garotas adolescentes. Em contraste, os quatro grupos de falantes adultos e o grupo dos garotos adolescentes apresentaram raras ocorrências do conector em apreço.

Interpretei tais resultados como indicando mudança por difusão, em que uma comunidade de fala adota uma inovação vinda de uma comunidade externa. Geralmente, os primeiros adotantes da forma inovadora são os indivíduos jovens, como aconteceu em Florianópolis. As garotas adolescentes parecem ser as líderes da mudança, uma vez que empregam o daí com grande frequência, ao contrário dos garotos da mesma faixa etária, que se comportam como os falantes mais velhos, pouco fazendo uso desse conector. ${ }^{25}$ Quanto ao grande uso do daí pelos pré-adolescentes, meninos e meninas, é possível que o processo subjacente seja não a difusão, mas sim, como já dito, a transmissão, questão que deve ser explorada posteriormente.

O processo de difusão do conector daí no português brasileiro parece vir acontecendo paulatinamente: há desde comunidades de fala em que seu uso já era intenso na década de 1990, a exemplo de Lages, a comunidades em que ele é pouco ou mesmo não utilizado, a exemplo de Natal (RN) (cf. TAVARES, 2018). Cabe, portanto, a realização de pesquisas em diferentes regiões brasileiras para a identificação de comunidades caracterizadas por diferentes estágios de difusão do daí, além de comunidades em que esse processo não tenha se iniciado. Além disso, fazem-se necessárias pesquisas que explorem fatores que podem ser relevantes para o processo de mudança, como o contato com indivíduos utentes de outros dialetos, o que pode ser averiguado por estudos que abordem as redes sociais e/ou as comunidades de prática ${ }^{26}$ a que se afiliam os informantes.

25 O foco deste estudo recai sobre o conector daí. Para uma discussão refinada sobre como o aumento de uso do daí entre os florianopolitanos jovens afeta os conectores $e$, aí e então, pode-se conferir Tavares (2003).

${ }^{26}$ Uma comunidade de prática é um conjunto de indivíduos reunidos em torno de um empreendimento comum. Meyerhoff (2006) aponta que se trata de uma unidade menor que a da rede social. Segundo a autora, a abordagem à comunidade de prática no âmbito da sociolinguística destaca o papel agentivo dos falantes. 
V. $9(3)$ 76-95 set-dez 2019

\section{Referências}

ANDROUTSOPOULOS, J. Research on youth language. In: AMMON, U.; DITTMAR, N.; MATTHEIER, K. J.; TRUDGILL, P. (Eds.). Sociolinguistics. An international handbook of the science of language and society. $\mathrm{V}$. 2, Berlin: de Gruyter, 2005. p. 1496-1505.

BUCHSTALLER, I. Diagnostic of age-graded linguistic behavior: the case of the quotative system. Journal of Sociolinguistics, v. 10, n. 1, p. 3-30, 2006.

CHESHIRE, J. Sex and gender in variationist research. In: CHAMBERS, J. K.; TRUDGILL, P.; SCHILLING-ESTES, N. (Eds.). The handbook of language variation and change. Oxford: Blackwell, 2003. p. 423-443.

COSERIU, E. Coordinación latina y coordinación románica. In:

Estudios de lingüística románica. Madri: Guedos, 1977. p. 203-231.

CUKOR-AVILA, P. Some structural consequences of diffusion. Language in Society, V. 41, p. 615-640, 2012.

; BAILEY, G. The interaction of transmission and diffusion in the spread of linguistic forms. University of Pennsylvania Working Papers in Linguistics, V. 17, n. 2, Selected Papers from NWAV 39, p. 41-49, 2011.

GUY, G. R. Variation and change. In: MAGUIRE, W.; McMAHON, A. (Eds.). Analysing variation in English. Cambridge: Cambridge University Press, 2011. p. 178-198.

GUY, G. R.; ZILLES, A. Sociolinguística quantitativa: instrumental de análise. São Paulo: Parábola, 2007.

HOPPER, P.; TRAUGOTT, E. Grammaticalization. Cambridge: Cambridge University Press, 2003.

KERSWILL, P.; CHESHIRE, J.; FOX, S.; TORGERSEN, E. English as a contact language: the role of children and adolescents. In: SCHREIER, D.; HUNDT, M. (Eds.). English as a contact language. Cambridge: Cambridge University Press, 2013. p. 258-282.

LABOV, W. The intersection of sex and social class in the course of linguistic change. Language Variation and Change, v. 2, p. 205-254, 1990.

2001.

Principles of linguistic change: social factors. Oxford: Blackwell, . Transmission and diffusion. Language, v. 83, n. 2, p. 344-387, 2007.

Principles of linguistic change: cognitive and cultural factors. Oxford: Blackwell, 2010.

MILROY, L. Social networks. In: CHAMBERS, J. K.; TRUDGILL, P.; SCHILLINGESTES, N. (Eds.). The handbook of language variation and change. Oxford: Blackwell, 2004. p. 573-600. 
MEYERHOFF, M. Introducing sociolinguistics. London: Routledge, 2006.

PAGOTTO, E. G. Variação e(é) identidade. Maceió: EDUFAL, 2004.

SANKOFF, D.; TAGLIAMONTE, S. A.; SMITH, E. Goldvarb X: a multivariate analysis application. Toronto: Department of Linguistics; Ottawa: Department of Mathematics. 2005. Disponível em http://individual.utoronto.ca/ tagliamonte/goldvarb.html. Acesso em 14 de outubro de 2017.

SILVA, W. P. B. Conectores sequenciadores E e AÍ em contos e narrativas de experiência pessoal escritos por alunos de ensino fundamental: uma abordagem sociofuncionalista. 2013. 120 f. Dissertação (Mestrado em Linguística). Programa de Pós-Graduação em Estudos da Linguagem, Universidade Federal do Rio Grande do Norte, Natal, 2013.

SILVEIRA BUENO, F. Grande dicionário etimológico-prosódico da língua portuguesa. São Paulo: Saraiva, 1965.

TAGLIAMONTE, S. A. So who? Like how? Just what? Discourse markers in the conversations of young Canadians. Journal of Pragmatics, v. 37, p. 1896-1915, 2005.

University Press, 2006.

Analysing sociolinguistic variation. Cambridge: Cambridge

Variationist sociolinguistics: change, observation, interpretation. Cambridge: Wiley-Blackwell, 2012.

; D'ARCY, A. Peaks beyond phonology: adolescence, incrementation, and language change. Language, v. 85, n. 1, p. 58-107, 2009.

TAVARES, M. A. A gramaticalização de E, AÍ, DAÍ e ENTÃo: estratificação/ variação e mudança no domínio funcional da sequenciação retroativopropulsora de informações - um estudo sociofuncionalista. 2003. 307 p. Tese (Doutorado) - Departamento de Letras, Curso de Pós-Graduação em Linguística, Universidade Federal de Santa Catarina, Florianópolis.

Mudança geracional versus difusão interdialetal: uma abordagem sociofuncionalista a conectores sequenciadores. Natal: UFRN, 2018. 92 p. 